\title{
O lugar da opinião. A cidade e os espaços de produção social da opinião pública
}

\author{
The place of opinion. The city and the spaces \\ for social production of public opinion
}

Maria da Penha Smarzaro Siqueira

Gilton Luis Ferreira

\section{Resumo}

Por mais que o termo possa induzir, o conceito de esfera pública não se encontra vinculado aos espaços de natureza pública fisicamente construídos. Mesmo assim, tendo como pano de fundo conceitual a obra do filósofo alemão Jürgen Habermas, Mudança Estrutural da Esfera Pública: investigações quanto a uma categoria da sociedade burguesa, o presente artigo se propõe identificar alguns ambientes que, na longa trajetória da história das cidades, serviram de palco para desenvolvimento das discussões e afirmação das ideias coletivas, buscando assim reconhecer lugares urbanos que historicamente embalaram a produção social da opinião pública e os novos ambientes midiáticos que a esse fim se propõem.

Palavras-chave: opinião pública; história urbana; esfera pública; cidades; espaço público.

\begin{abstract}
As much as the term "public sphere" may induce us to think that this concept is bound to physically built public spaces, this is not actually true. In spite of this, having the work of the German philosopher Jürgen Habermas, "The Structural Transformation of the Public Sphere: An Inquiry into a Category of Bourgeois Society" as the conceptual background, this article aims to identify some environments that, in the long trajectory of the cities' history, served as a stage for the development of discussions and for the affirmation of collective ideas. Thus, it aims to recognize urban places which have historically involved the social production of public opinion and the new media environments that have this purpose.
\end{abstract}

Keywords: public opinion; urban history; public sphere; cities; public space. 


\section{Introdução}

0 conceito de esfera pública não apresenta um formato inflexível ou definitivo, sua mobilidade conceitual depende do espaço social onde se localiza ou do tempo histórico em que se inscreve. Assume o encargo sociológico de descrever instituições e práticas sociais efetivas, bem como fornece critérios para análise e julgamento dessas mesmas práticas e instituições.

No entendimento de Habermas (2003), a esfera pública burguesa se formava pela reunião de pessoas privadas, em ambiente de acesso público para discutir questões privadas publicamente relevantes. A estruturação dessa esfera ancorava-se na capacidade de racionalização pública ao alcance dos indivíduos que intercambiavam. Como categoria histórica, a esfera pública teve origem vinculada à dinâmica da sociedade burguesa em contraposição ao poder estabelecido, com interesse de assegurar um Estado de direito que garantisse as condições necessárias ao desenvolvimento e ao livre fluxo de ideias, mercadorias, trabalho e informações sem a intervenção de outras esferas, principalmente a estatal.

Do ponto de vista semântico, o termo esfera pública pode induzir em erro se sugestionar uma representação espacial, um espaço de uso comum fisicamente construído como ruas, praças ou prédios públicos. Também não se confunde com a esfera do Estado, negando-se a comparação com o âmbito do poder público, uma vez que não diz respeito aos espaços de exercício do poder com todos os seus órgãos e aparelhos administrativos. Nesse sentido, a esfera pública não se apresenta como espaço fisicamente construído, mas como ambiente socialmente edificado.
Sem desconsiderar tais premissas, as discussões geradoras da opinião pública jamais abdicaram de um locus para sua produção ou recusaram ambientes propícios para seu desenvolvimento e difusão. Dos tempos imemoriais da antiguidade grega - tendo a Ágora como espaço de conversação e debate - ao contemporâneo ciberespaço, passando pelo espaço literário, imprensa, bares e cafés, a esfera pública sempre esteve associada a um "palco" onde se desenrolaram as transformações ou permanências das opiniões ali produzidas. No texto, reconhecemos ambientes que na longa duração se fizeram propícios ao desenvolvimento do debate e consolidação das ideias e opiniões coletivas. 0 breve passeio pela trajetória dos espaços de convivência pública nas cidades ambiente favorável ao convívio produtor de sociabilidades e opiniões - possibilitou identificar características e práticas sociais exercidas nesses referidos espaços que foram utilizadas para consolidar, fomentar e enriquecer o que se convencionou chamar de opinião pública.

\section{A cidade como palco histórico da opinião pública}

No universo sócio-histórico, ritual e linguagem muito têm a nos dizer, principalmente porque o contexto simbólico que abriga a evolução dessas manifestações é muito rico na história da humanidade. No entanto, essa riqueza cultural pouco se registrou na longa duração e nem sempre foi devidamente considerada no processo de reconhecimento das comunidades humanas embora, historicamente, a aliança entre linguagem e rituais tenha demarcado 
mediações na construção da sociabilidade humana. Quando Mumford (2004) se refere aos santuários e cemitérios expressa o importante simbolismo desses elementos na construção dos rituais e na representação maior dos rituais por seu valor de linguagem, construção e transmissão cultural de uma comunidade, de um povo ou de um lugar, ou seja, " [...] tudo isso tem algo a ver com a natureza da cidade histórica" (Mumford, 2004, p. 15).

Aquilo que historicamente produzimos como expressão da cidade muito mais se vincula ao ambiente fisicamente construído do que tradições e práticas sociais ali edificadas, uma carência conceitual que - guardadas louváveis exceções - se reflete ao longo da produção acadêmica acerca da ideia de cidade. Apreender a cidade em sua totalidade diz respeito à compreensão do processo que abarca a inserção histórica do homem no seu lugar, uma vez que as cidades agregam à sua constituição - além de pedra e tijolos - significados simbólicos produzidos pela trajetória dos indivíduos que nela habitam. Nesse sentido,

[...] situaremos em bases falsas todo 0 problema da natureza da cidade, se procurarmos apenas estruturas permanentes, amontoadas por trás de uma muralha. Para chegar mais perto das origens da cidade, cumpre-nos suplementar o trabalho do arqueólogo que procura a mais funda camada na qual possa reconhecer uma obscura planta baixa, a indicar a existência de uma ordem urbana. Se quisermos indicar uma cidade, devemos seguir a trilha para trás, partindo das mais completas estruturas e funções urbanas conhecidas, para os seus componentes originários, por mais remotos que se apresentem no tempo, no espaço e na cultura, em relação aos primeiros tells que já foram abertos. Antes da cidade, houve a pequena povoação, o santuário e a aldeia, 0 acampamento, 0 esconderijo, a caverna, o montão de pedras; e antes de tudo isso, houve certa predisposição para a vida social [...]. (Munford, 2004, p. 11)

Sendo verdade que antes da cidade houve a sociabilidade, concordaremos com os gregos quando afirmavam que fundar e erguer uma cidade e ordenar seu território não eram os únicos pré-requisitos à sua constituição, a política e as relações sociais influenciavam formato, uso e ocupação dos espaços. Nesse alinhamento, a maior contribuição herdada dos gregos foi a própria polis, forma política original com participação dos cidadãos na defesa e gestão dos assuntos comuns à cidade, bem como as instâncias de decisões coletivas e a tarefa de mediação e arbitragem dos conflitos produzidos pela convivência cotidiana. Outro legado que a antiguidade grega produziu foi a clara distinção entre oikos - esfera privada pertencente ao universo doméstico - e polis esfera pública comum aos cidadãos livres. No entanto, a Ágora talvez seja o ambiente que nesse período melhor incorporava a ideia de espaço da construção de opiniões, tanto que inicialmente o termo designava o ato de se reunir, refletir e debater sobre assuntos comuns passando depois a representar, concomitantemente, um espaço físico livre de edificações, delimitado por mercados e feiras, assim como por edifícios de caráter público, o que equivaleria atualmente a uma praça. Portanto, a Ágora apresentava-se como expressão máxima da esfera coletiva na urbanística grega, sendo o espaço público por excelência. É nela que o cidadão grego convivia com o outro, onde ocorriam discussões políticas e tribunais populares, 
portanto espaço da livre opinião, locus originário da ideia de cidadania, mesmo que reconheçamos o caráter restritivo do que se entendia por cidadão naquele período.

Habermas (2003), da mesma forma que Hannah Arendt, em $A$ condição humana, navega pela polis grega observando o comportamento dos cidadãos na prática da vida pública, motivado pelo desejo de buscar no padrão grego fundamentações históricas dos conceitos de público e privado, sedimentados no pensamento europeu, identificando como esfera pública o espaço onde os cidadãos livres e iguais - condição fundamental para o exercício da política no sentido latu - compartilhavam práticas esportivas, valorizavam a cultura, realizavam disputas e discussões, corroborando que o lugar do exercício da convivência comunitária era o lugar de produção da opinião. Assim, a Grécia praticamente institucionalizou a opinião pública articulando os recursos intelectuais com os recursos que o espaço urbano oferecia - a assembleia, o tribunal, a praça, etc. - para aperfeiçoar a comunicação e produzir opiniões que depois de debatidas se estabeleciam, se difundiam e se impunham na vida coletiva.

Roma - constituída sob forte herança etrusca e helênica - influenciou diversas culturas em diversos campos da vida social e da organização do espaço urbano. 0 poderio militar proporcionou a conquista de novos territórios, mas foi utilizando o urbanismo como instrumento político que o império assegurou a romanização das novas ocupações. Em outros termos, a expansão do Império Romano se deu com o avanço das novas fronteiras territoriais e imposição dos símbolos que garantiam a onipresença do sistema político e social que emanava do poder central e difundia um conjunto de costumes e traços culturais às mais distantes terras conquistadas.

Um forte traço cultural é retratado por Macedo (1986, p. 3), segundo o qual o papel da opinião pública não desaparece no Império romano, pois "[...] em face das exorbitâncias nefastas dos imperadores, desencadeia-se a opinião pública e eles acabam por serem vencidos e substituídos". Não interessa ao autor o modo como isso tenha ocorrido, sua preocupação é discutir que esses acontecimentos mostram que a opinião pública se tinha separado dos canais oficiais, ganhado as ruas e aparecendo dotada de autonomia, ainda que precária.

0 referido autor também defende que podemos dizer, sem prejuízo de outras civilizações, que da poesia ao púlpito, das ruas às praças públicas, a Europa passou a se instituir como uma civilização em que a opinião pública é uma dimensão intrínseca à sua própria vida pública, manifesta ou subjacente, porém sempre presente. Seu processo civilizatório e seus inumeráveis conflitos ao longo da história não podem ser entendidos sem a opinião pública e a existência dos elementos indispensáveis e complementares à sua formulação e difusão, assim como à sua permanência, imposição ou valor.

Filiando-se ao pensamento de Habermas (2003), Lubenow (2007) nos diz que na Idade Média a contraposição entre público e privado não tinha vínculo de obrigatoriedade, não havendo separação entre as duas esferas. 0 que existia era um conceito de representação que vinculava indivíduo à autoridade, numa representação pública da autoridade. Essa representatividade pública não se constituía num setor social, mas se referia a algo como um status. 
Nesse sentido, a representação só podia ocorrer na esfera pública, não havendo nenhuma representação que fosse coisa privada.

Neste modelo da "esfera pública estruturada pela representação" não podemos falar da esfera pública como um domínio social na verdadeira acepção da palavra. Ela desempenha antes de tudo o papel de ser signo característico de um estatuto e não existe enquanto coisa privada. Neste novo cenário, a cidade veio a perder alguma da sua centralidade à medida que o poder de decisão se centrou cada vez mais na corte. $A$ cidade tende assim a ficar limitada a uma atividade aclamativa face aos senhores feudais enquanto representantes locais do poder real. (Eirógomes e Duarte, 2005, p. 614)

Na sociedade medieval prevalecia o domínio da religiosidade e o espaço público tinha uma estrutura complexa, ele não congregava um centro norteador de referência pública, sendo os espaços distribuídos de acordo com sua funcionalidade. Entre o centro civil - com o palácio como representação do poder econômico e político - e o centro religioso, com a catedral e o palácio episcopal, esse último, predominava e simbolizava a maior expressão de poder e de congregação de valores (Benevolo, 2001). Ainda na configuração da sociedade medieval, de acordo com Narciso (2008, p. 60), “ [...] o espaço público era regido pelo privado (senhor feudal) que defendia os interesses coletivos. Ou seja, apesar de ser público era regido pelo poder privado".

Le Goff (1999), num percurso sobre a cidade medieval, suas funções e simbolismos expressa as representações que saem de cena e aquelas que vão dominar o universo socioespacial, expressando a ausência de um espaço comum como espaço público agregador do diálogo e disseminador de ideias.

[...] As funções da cidade mudaram [...] os sinos aparecem e se instalam no século VII no Ocidente. Eles serão pontos de referências da cidade. Quanto ao anfiteatro, ele foi abandonado, já que o cristianismo não ocidental não admite mais o circo. [...] 0 estádio não tem mais razão de ser: o esporte toma formas completamente diferentes. Reservado à classe nobre, ele se torna essencialmente um exercício militar. As termas desaparecem, já que se estabelece uma nova relação com o corpo, assim como novas formas de higiene e sociabilidade. [...] Ao lado da região das antigas termas, em que as pessoas se lavavam, sentava-se às mesas das tabernas, onde se discutia: elas também não têm mais razão de ser. Além do mais, a praça pública muda de estatuto. Nada de fórum! Não temos mais o lugar central em que os cidadãos se encontram [...] apaga-se este hábito de discutirem conjunto os negócios da cidade ou os negócios privados. Quando há encontros e discussões, isso se dá com mais frequência nas igrejas [...]. (Le Goff, 1999, p. 11)

Com a fragmentação e a desintegração das estruturas políticas e econômicas do Absolutismo e do Feudalismo, combinado com 0 início do modelo capitalista de produção, inaugura-se a potencialização das capacidades humanas em produzir mercadorias, tecnologias, serviços e informações. A partir da Revolução Industrial ${ }^{1}$ a humanidade experimenta, pela primeira vez na história, capacidade de produção em série e desenvolvimento em larga escala. Sob o governo da burguesia, mesmo com forte conteúdo classista, se afirmam tanto a liberdade econômica quanto política, fatores semelhantes que irão possibilitar o surgimento 
do indivíduo moderno. Nesse novo ambiente, o citadino - que testemunha em meio às multidões um mundo em processo de modernização - foi impelido a desvendar infinitos códigos num universo repleto de imagens, tão distinto de seu ambiente agrário original. Assim,

[...] as transformações econômicas e sociais deixam, nas cidades, marcas ou sinais que contam uma história não-verbal pontilhada de imagens, de máscaras que têm como significado o conjunto de valores, usos, hábitos e crenças que nutriram, através dos tempos, o quotidiano dos homens. (Ferrara, 1990, p. 3)

Um processo inexorável ao capitalismo que, conforme Pesavento (1997), possibilita aos indivíduos a sensação de experimentar a vivência de dois distintos mundos, um que se dá a conhecer e se faz com rapidez e outro que, ao aparentar-se sólido, é transposto pelo novo. É nessa ambiência, com o surgimento de uma nova ordem social, que na era moderna se estabelece tanto o Estado como o mercado, instituições estruturantes do novo sistema onde a esfera pública se consolida de modo diferenciado.

Num processo de longa duração histórica as mudanças estruturais e os novos paradigmas que consolidaram a sociedade moderna burguesa vão configurar novos elementos na dinâmica urbana das cidades, mudando os significados do espaço público. Nesse sentido, o espaço público expressa a representação da modernidade como espaço livre acessível à circulação e participação de vários sujeitos sociais na construção da sociedade moderna (Resende, 2005).

\section{Cidade moderna, berço da opinião pública burguesa}

A transformação dos espaços físicos urbanos e das sociabilidades durante os séculos XVIII e XIX pode ser tratada a partir da análise do processo de profundas mudanças que viveu a Europa nesse período. Surgia a sociedade baseada na ideologia liberal que nasceu e içou ao poder uma burguesia politicamente excluída do Antigo Regime, mediante um processo de Revoluções Burguesas ${ }^{2}$ que tiveram lugar de destaque, principalmente, na França, Alemanha e na Inglaterra. É desse ambiente que Habermas (2003) parte para fazer sua leitura e ao interpretá-lo nos avisa referir-se, a esfera pública burguesa, a uma categoria pertencente a um dado momento histórico que não poderia ser imaginada ou transposta para uma análise fora do contexto dessa mesma sociedade.

A esfera pública é tratada pelo autor como a terceira instituição da modernidade capitalista, não se confundindo com o Estado e nem com o mercado. Os atores que consolidariam esse "público" seriam os representantes letrados da burguesia, sujeitos com capacidade de racionalizar, construir e manifestar uma opinião sobre os fatos de interesse coletivo. Dessa forma, o autor coloca a opinião pública como um modo de ver determinada coisa e analisá-la com relevante função de controlar o exercício do poder político. A capacidade de racionalização desse público conduzirá ao julgamento da coisa debatida e, por sua vez, aquilo que é objeto de julgamento é o que ganhará publicidade em forma de síntese ou consenso, tornando 
a esfera pública - para a tese democrática - 0 ambiente de legitimação do poder e da opinião pública. Assim, defende o autor que

[...] a arte do raciocínio público é aprendida pela vanguarda burguesa da classe média culta em contato com o "mundo elegante", na sociedade aristocrática da corte que, é verdade, à medida que 0 moderno aparelho de Estado se autonomizava em relação à esfera pessoal do monarca, separava-se por sua vez cada vez mais da corte, passando a constituir um contrapeso na cidade. A "cidade" não é apenas economicamente 0 centro vital da sociedade burguesa; em antítese política e cultural à "corte", ela caracteriza, antes de mais nada, uma primeira esfera pública literária que encontra as suas instituições nos coffee-houses, nos salons e nas comunidades de comensais. (Habermas, 2003, pp. 44-45)

É justamente nessa ambiência da modernidade burguesa, norteada pelo mercado, que surge uma esfera pública de conteúdo não estatal e sua expansão está diretamente vinculada ao crescimento das cidades e das utensilagens que o universo urbano pode ofertar às novas formas de sociabilidades, às práticas sociais e à produção da opinião. Nos princípios dessa sociedade

[...] o tornar "público burguês" já traz a noção de uma necessidade e melhor articulação de interesses entre Estado e cidadão. Noção que ganha legitimidade num segundo momento, já a partir da segunda metade do século XVIII, quando surge a categoria da opinião pública. É aí que se pode falar de um grande salto na noção que se tem de espaço público. (Resende, 2005, p. 131)
Nesse contexto, amplia-se o significado do espaço público com o surgimento de novos atores sociais e novos lugares de encontros que "dão voz a opiniões e discussões muitas vezes controversas às do Estado" (Resende, 2005, p. 131). Complementa o autor que 0 movimento sócio-histórico da sociedade moderna e os condutores sociais, econômicos e políticos da sociedade capitalista, vão promover várias mudanças nas cidades da Europa, principalmente a partir de meados do século XVIII, com a grande circulação do ideário do progresso que se expandiu nas sociedades ocidentais. Dessa forma, o mundo capitalista na sociedade contemporânea reconfigura 0 espaço público, pelo viés do significado burguês, pleno de arranjos e com grande diversidade de atores sociais.

Por sua vez, Guedes (2010) afirma que desponta uma nova noção de espaço público, como um lugar de múltiplas vozes, com novos paradigmas tanto nas formas de participação quanto na diversidade das representações sociais. A dinâmica capitalista e a complexidade contemporânea mudam o perfil das relações sociais no espaço público, facilitado pelas mudanças que se processaram tanto no âmbito das relações entre Estado, outras formas de poder e sociedade civil, quanto pela mediação promovida pela tecnologia.

A mediação facilitada pelas tecnologias - a partir da segunda metade do século XX - somada a outras variáveis contribui para a pluralização do espaço público contemporâneo. As inúmeras formas de comunicação e de informação que 0 atravessam e 0 sustentam permitem a compreensão de um mundo que 
vai além das experiências pessoais e 0 transformam em um campo de muitas vozes, em uma arena de interesses convergentes e divergentes. (Guedes, 2010, p. 7)

Nessa perspectiva, nos reportamos a Habermas (2003, p. 232) quando expressa "que o âmbito da competência da esfera pública se ampliou", mudando o simbolismo e os significados do espaço público.

Coadunando com o autor, as mudanças estruturais no sentido tradicional do "público" passam por transformações se estendendo às recentes funções do espaço urbano. Em outros termos, à medida que a cidade assume suas novas funções "[...] modifica-se não só o sustentáculo da esfera pública, mas ela mesma se modifica" (Habermas, 2003, p. 46). Assim, as várias cidades da Europa, que na segunda metade do século XIX e no limiar do século XX, passaram por profundo processo de mudança estrutural tiveram afetadas tanto a noção funcional do espaço público, como o processo de produção da opinião pública. 0 fenômeno da modernização urbana das cidades europeias teve Paris como a grande referência, sendo a cidade que desempenhou um determinante papel nesse novo ciclo impulsionado por Napoleão III, logo após sua ascensão ao poder.

É o quadro que colheram os pintores impressionistas como Monet e Pissarro em suas visitas aos boulevards parisienses do alto, cheios de gente. É um ambiente ainda diferenciado, onde as formas singulares podem ser colhidas somente perdendo sua individualidade, misturando-se em um tecido compacto de aparências mutáveis e precárias; mas isso constitui o ponto de partida do qual irá surgir o conceito de ambiente urbano aberto e contínuo, oposto ao antigo e fechado. (Benevelo, 1998, p. 110)

Uma voz dissonante poderia, contudo, contra-argumentar dizendo que, da mesma forma que Paris no século XIX, Londres também já tinha se constituído em metrópole e que os contrastes e transformações do espaço e das sociabilidades urbanas estavam também ocorrendo em outras cidades europeias de porte. No entanto, Pesavento (2002, p. 31) entende que a capital francesa se fez "[...] metonímia da modernidade urbana em função da força das representações construídas sobre a cidade, seja sob a forma de uma vasta produção literária, dos debates e opiniões daí derivadas, seja pela projeção urbanística dos seus projetos [...]". Mais do que a reformulação das estruturas urbanas, o processo de modernização materializou nas cidades o ideário da modernidade burguesa instituindo-o como representação das relações sociais nelas estabelecidas.

No contexto deste novo modelo, em que as discussões críticas da burguesia decorrem em espaços semi-públicos da cidade como os Salões, as Coffee Houses, as Tabernas, etc., a esfera pública burguesa parece voltar a centrar-se em torno da cidade. Na justa medida em que proporciona os espaços necessários para a formação de uma opinião pública, a cidade readquire alguma da centralidade que havia perdido com a esfera pública representativa. (Eiró-Gomes e Duarte, 2005, p. 614) 


\section{Figura 1 - O Boulevard Montmartre em 1897}

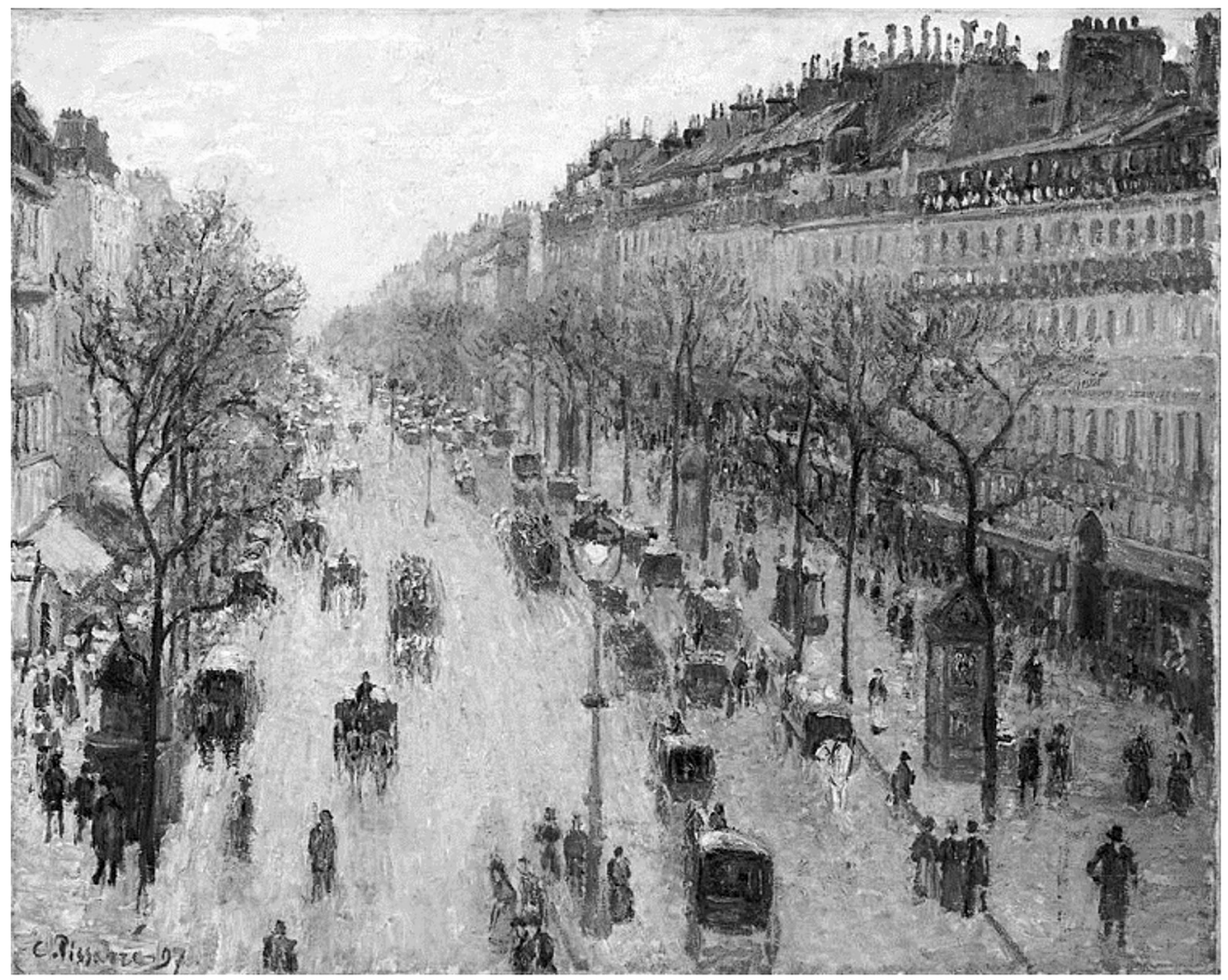

Fonte: Metropolitan Museum of Art. Obra: O boulevard Montmartre em uma manhã de inverno. Autor: Camille Pissarro, 1897. Disponível em http://en.wikipedia.org/wiki/Camille_Pissarro.

Segundo Perlatto (2012, p. 80), nesse processo a burguesia se estabelece "[...] como a primeira classe governante cuja fonte de poder localiza-se no âmbito privado, independente do controle do Estado [...]". Requerendo ter ciência de tudo o que ocorre na esfera estatal, essa classe conduz o movimento no qual o Estado necessita legitimar-se publicamente à crítica racional. Embora concorde que a evolução da esfera pública tenha ocorrido junto com a expansão da cidade moderna, sustenta que sua constituição definitiva se deu a partir da transformação da função da imprensa que, como arena externa ao universo estatal, auxiliou a construção " [...] de uma opinião pública crítica capaz de colocar publicamente a questão da legitimidade discursiva do Estado". 


\section{Universo urbano e utensilagens de produção e difusão da opinião pública}

A dinâmica do mundo moderno transformou a fisionomia das cidades, suas práticas e relações sociais e intensificou o fluxo de pessoas e de mercadorias pelo mundo afora. A necessidade de mais e melhores informações dinamizou 0 processo comunicacional e passou a exigir da imprensa novo posicionamento quanto a oferta de informações especializadas, solicitando também postura inovadora na forma de exposição de ideias. Da mesma maneira, a intensificação do acesso das populações aos processos de escrita e leitura demandou maior intensidade nas trocas de informações, ampliou o espaço de conversação e debate e deslocou o lugar de produção social da opinião pública para ambientes diferenciados.

[...] Se, de início, o espaço público era o local das discussões políticas, da formação de opiniões e da legitimação do poder, com a imprensa ocorreu o deslocamento desse espaço para os jornais. A imprensa foi a primeira instância mediadora do espaço público, antes concretizado pelos debates em clubes, ruas e praças. No entanto, como os meios de comunicação não atendem a todos os segmentos sociais que desejam ou tentam participar do debate estabelecido na mídia, os grupos excluídos da esfera midiática são, por consequência, excluídos do espaço público. Ou seja, a imprensa favoreceu a "privatização do espaço público". Porém, é interessante observar que sempre houve e possivelmente sempre haverá excluídos do espaço público, aqueles que por alguma razão não estiveram aptos a discutir e polemizar, seja por razões econômicas ou educacionais. (Melo, 2005, p. 3)

Antes de nos reportarmos ao deslocamento dos espaços de discussão política e formação de opiniões das ruas para a imprensa, conforme texto supracitado, é importante ressaltar que o entendimento da autora de que sempre existiu e da possibilidade de permanecer existindo os chamados "excluídos do espaço público" corrobora com Ota (2013) quando apresenta críticas à obra habermasiana realizada por Iris Marion Young, Peter Howhendahl, Nancy Fraser, Seyla Benhabib quando realizam revisão teórica acerca da esfera pública. Argumentações de Fraser (1996), apresentada por Losekan (2009, p. 44), dizem ser utópica a ideia de igualdade nas relações na esfera pública da forma defendida por Habermas (2003), uma vez que o suporte desse "público" está caracterizado, fundamentalmente, como o burguês letrado, notando, assim, uma incongruência na aplicação do conceito em se tratando de uma sociedade estratificada e multicultural. A autora acredita não ser possível aos interlocutores abandonarem suas diferenças estruturais e se comportarem como iguais em um processo dialógico na esfera pública. Com fina ironia, afirma que, para a concretização da proposta de Habermas, as desigualdades sociais deveriam ser eliminadas, uma vez que essas desigualdades determinam posições hierarquizadas que não desaparecem na esfera pública. Em outros termos, se um indivíduo toma parte em um debate público ele simplesmente não deixa de lado sua posição social, sendo que esta é que forja sua vida e identidade, estando assim refletidas na esfera pública as posições assimétricas de acesso à 
riqueza, ao poder, à cultura e ao prestígio das sociedades estratificadas.

Retomando o tema dos espaços de produção da opinião pública no final do século XVII e início do XVIII - quando aumenta o interesse da sociedade em participar do processo de decisão daquilo que entendia lhe dizer respeito, bem como o desejo de forçar o poder a justificar-se -, a imprensa consegue se tornar periódica ampliando suas fronteiras para além das pautas culturais inserindo-se nas temáticas políticas e sociais. Assim, seu papel de produtora e difusora dos debates acerca do interesse comum ganha forte centralidade, ao mesmo tempo em que promove um novo lugar de "conversação" capaz de amplificar e difundir as discussões do tempo presente. 0 advento da imprensa fomenta um ambiente que se difere dos espaços públicos de produção direta da opinião - se porventura assim pudermos chamar as ruas, praças e cafés - e, conforme defende Thompson (1998), carrega consigo o atributo de mediar a inscrição dos fatos na história.

0 jornal foi o recurso tecnológico moderno que inaugurou o processo de informação sobre a cidade, mas foi juntamente com o rádio e a televisão que formaram um conjunto midiático cuja aparição foi decisiva para a instauração da noção moderna de esfera pública, ensina Canclini (2002, pp. 45-46). Baseado em estudos acerca de periódicos na cidade do México, constata que na imprensa é o Estado quem mais "fala" sobre os temas relativos à cidade; que os jornais contribuem para a construção da imagem de uma cidade focada nas regiões centrais, reproduzindo saberes convencionais, sendo um meio com mais elementos discursivos que outros para refletir sobre a cidade e elaborar a condição de cidadão, mas que não contribui para expandir a visão sobre a cidade; assim, a maioria dos jornais insiste no que já é habitual, prolongando estereótipos formados historicamente.

0 autor afirma ainda que, nas primeiras décadas do século $X X$, o rádio auxiliou na consolidação das nações sendo útil para os imigrantes conhecerem a língua local e as cidades, as notícias e diferentes formas de expressar os sentimentos na vida urbana e que, nas últimas décadas do referido século, o rádio tornou-se um dos lugares da expressão cidadã. No entanto, mesmo quando o circuito radiofônico se abre e o cidadão comum passa a assumir algum protagonismo, não se pode simplesmente afirmar que esse modo amplia a participação cidadã nos assuntos públicos, uma vez que os condutores de tais programas, mesmo quando há participação direta dos cidadãos, quase sempre traduzem as declarações dos ouvintes para integrá-las em um discurso homogêneo; em alguns casos, selecionam e reelaboram para adequá-las aos objetivos da emissora. As tendências habituais são reduzir a complexidade do discurso radiofônico ao máximo possível e situar as opiniões diversas em um consenso imaginado como se compartilhado fosse pela maioria.

0 rádio propicia a expressão de seus ouvintes em troca do reconhecimento de sua credibilidade. Permite que a "cidadania" fale, mas esta deve deixar-se limitar, orientar e, até mesmo, censurar. No fim das contas, resta a dúvida de quanto 0 rádio concede para que se estenda a esfera pública, e o quanto procura através da idéia de "livre expressão" testemunhos que legitimem seu lugar no mercado das comunicações. (Canclini, 2002, p. 47) 
Sobre a televisão, Canclini (2002) relata que esse meio é, em certo sentido, reflexo do que ocorrera com as megalópoles nas últimas décadas, um veículo que cresceu aceleradamente chegando a $95 \%$ dos lares. 0 crescimento caótico da cidade suprimiu a possibilidade de imaginá-la como um conjunto. 0 que é possível saber sobre a megacidade nos chega mais pelo olhar "onisciente" da TV tentando recompor o sentido global da vida cidadã - do que pelas experiências diretas do cidadão que pela cidade possa passear e apreendê-la. Apoiando-se em pesquisas de Vernik (1996) e Silva (1996), Canclini (2002) oferece versões distintas e complementares das estratégias televisivas para afirmar-se como espaço de interação comunitária. 0 primeiro autor diz que a comunicação midiática tem significados e repercussões diferentes em grupos de distinta localização econômica e sociocultural. A informação é recebida de forma diferenciada de acordo com os recursos de modernidade que o cidadão dispõe, segundo a possibilidade de vincular-se não só ao território residencial, mas com outras regiões da cidade. A TV seria o espaço que a modernidade mass-midiática reservou aos excluídos. Para Silva (1996), as notícias são produzidas para um público distante do local dos acontecimentos. Os fatos são incorporados como parte de uma realidade, aceitável na medida em que oferece um espetáculo distante. Não altera a rotina diária, não tem pretensões realistas da representação fotográfica, nem propriedades estéticas do relato literário, muito menos a força causal da explicação histórica. São relatos virtuais midiáticos que servem para fantasiar e tais fantasias servem para "desrealizar". Assim, a TV prende fantasias cidadãs que poderiam levar "a mudanças sociais inesperadas".

Outro debate que se coloca acerca das práticas de produção e difusão da opinião pública é a virtualização das relações sociais. Com o desenvolvimento das novas tecnologias de informação ocorrida nas últimas quatro décadas, o mundo experimentou um vertiginoso crescimento no campo tecnológico que permitiu grande expansão de ambientes virtuais, que por sua vez não fazem desaparecer os lugares fisicamente construídos capazes de abrigar o debate público, porém criam novos espaços de intercâmbio e convivência social. Com certeza, as potencialidades dessas redes de interação eletrônica ampliaram-se em vários níveis (governamental, privado, sociedade civil) e direções (educacional, cultural, política, entretenimento), dentre tantas outras. Com o crescimento da Internet, em especial, ocorreu também uma expansão de "movimentos sociais" com diversos graus de formalização ou quase completamente informais, com organização individual ou coletiva, muitas vezes sem uma face ou identidade reconhecidas e de coloração política e ideológica variada ou amorfa. Alguns apostam e renovam as esperanças nesta nova Ágora no sentido de estabelecer ou resgatar os fóruns de debate público, por meio da interação de novas comunidades apoiadas em novos mecanismos de interação. Essas redes de sociabilidades podem ampliar-se focadas em diversos objetivos, com lógica de funcionamento e temas variados, criando redes de solidariedade, protesto, reivindicação e cooperação ou, como já preveem os analistas do cotidiano, podem simplesmente desfazerem-se ou tornarem-se obsoletas tão rapidamente quanto surgiram. 
Nascimento (2002, p. 6) esclarece que esses movimentos têm a capacidade de expor problemas sociais que se tornam "invisíveis" nos meios de comunicação tradicionais, criando meios alternativos que estabelecem condições para a "ação política coletiva em moldes mais rápidos, organizados e menos dispendiosos, estimulando o desaparecimento de intermediários que distorcem a informação, como os jornalistas e os políticos", ou seja, criando uma Ágora virtual de produção da opinião pública livre do caráter mediado presente nas arenas políticas, no rádio, jornal e televisão. No entanto, a autora também alerta que as características tecnológicas desses ambientes públicos virtuais prometem um eldorado de individualidade, plenos recursos informacionais, possibilidades ilimitadas de expressão, participação e interação permanente com os demais cidadãos e com o próprio poder político, caindo assim no ideal utópico da esfera pública habermasiana.

Em particular, estas visões idealizadas de revitalização da esfera pública suscitam um primeiro conjunto de problematizações, que se prendem com uma crítica a retóricas de regeneração das comunidades e dos movimentos cívicos ou sociais, das suas lógicas de funcionamento, sejam 'virtuais' ou físicos. Ao associar comunidade a comunicação, enquanto transparente e harmoniosa, estamos perante uma idealização política da primeira, segundo a crítica formulada por Kevin Robbins (1999), projetando uma 'ilusão do consenso e da unanimidade' que traduz as formulações de Habermas de uma esfera pública de discussão consensual, racional e crítica, mediante os contributos de todos os participantes. Especificamente nos espaços electrónicos, estes não incluem apenas espaços organizados e concretos de debate entre outros definidos, mas também podem constituir-se enquanto vastos, caóticos, com uma variedade complexa de intervenientes, sem objetivos claros e sem obedecer a regras racionais de argumentação. (Nascimento, 2002, p. 6)

Freitas, Mamede e Lima (2002), discutindo os espaços de fluxo em projetos de cibercidades dizem que Castells (1999) propõe a ideia de uma nova forma espacial presente nas práticas sociais contemporâneas que o próprio cunhou como "sociedade em rede". 0 autor constrói a concepção de espaço de fluxos, como sendo a organização material das práticas sociais que tem por base o tempo compartilhado funcionando por intermédio de fluxos, sendo esses entendidos como sequências intencionais, programáveis e repetitivas de trocas e relações recíprocas entre posições desarticuladas fisicamente, garantidas por atores sociais tanto nas esferas econômica, política e cultural como no campo simbólico da sociedade. Em outros termos, trata da transição das práticas sociais da sociedade industrial para as novas relações estabelecidas na sociedade da informação, onde os espaços estão sendo transformados em fluxos informacionais que afetam diretamente a forma de socialização dos atores sociais.

Essas novas práticas sociais desenvolvidas em ambientes virtuais, especificamente em projetos de cibercidades, apresentam uma diferença fundamental em relação aos ambientes físicos. Os autores supracitados, baseados em Graham (1995), afirmam que elas ocorrem em uma única direção, carecendo de oportunidade de debate, não se caracterizando, dessa forma, como um "espaço público", pelo fato 
de geralmente não retratarem as tensões e problemas sociais e ambientais presentes na cidade física em que se espelham, por se apresentarem fragmentadas, sem contato com 0 domínio urbano físico que representam e sem a conexão com as demais cidades virtuais.

[...] Nos parece também utópico achar que a comunicação mediada por computadores irá substituir 0 contato face-a-face em áreas urbanas específicas, como parte da implantação do tele-trabalho, acesso a serviços públicos, redes de saúde e educação. [...] 0 que temos observado é que, paradoxalmente, é a intensa "rede local" das cidades e as interações face-a-face que têm alimentado as contínuas inovações na Internet, na mídia digital, derrubando as teorias do fim das distâncias pelos entendidos da indústria e da mídia. (Freitas, Mamede e Lima, 2002, p. 5)

Que as novas tecnologias da informação têm exercido influência sobre os lugares urbanos físicos de produção e difusão da opinião é tão certo como dizer que essa influência ao invés de torná-los supérfluos acaba por instituir certa interdependência, ou seja, o ambiente virtual deve ser compreendido como extensão do intercâmbio humano, de suas instituições e de suas utensilagens de interação, conversação e debate, jamais como substituição ou eliminação do mesmo.

Na realidade não se trata da substituição radical dos ambientes de interação social. 0 que percebemos é apenas uma mudança de rumo promovida pelos homens na construção da própria história; mais uma esquina histórica na vida de suas cidades. Uma mudança de rumo talvez tão intensa quanto a que Habermas (2003) identificou, ao perceber que a modernidade burguesa retirou da esfera privada o debate de interesse público e o levou às ruas e praças, transformando-as em lugares de produção da opinião. Essa mudança estrutural do lugar de produção da opinião pública acaba ocorrendo no exato período em que os próprios espaços urbanos passaram a integrar 0 universo dos interesses burgueses, quando 0 fenômeno da modernização urbana, iniciada nos países europeus e rapidamente universalizado, respondeu às imperiosas necessidades de expansão das fronteiras comerciais e financeiras de uma nova fase da produção capitalista, proporcionando o surgimento de novos espaços e formas de interação.

De maneira bem similar às mudanças que contemporaneamente vem ocorrendo no cruzamento entre espaço e sociedade - materializado nas crescentes interações sociais em ambientes virtuais -, também percebemos que no movimento de remodelação dos espaços urbanos, ocorrido como fenômeno mundial há mais de dois séculos, não houve nenhuma mudança abrupta. A história das cidades geralmente não dá saltos, descreve trajetória. São as transformações no ordenamento social que influenciam na reconfiguração dos espaços e nas formas de produção da opinião. Assim, esses novos territórios e utensílios de produção da opinião são filhos de uma, igualmente, nova ordem social.

\section{Considerações finais}

Interrogar o passado das cidades conduz, inexoravelmente, ao vasto universo de processos promovidos pela condição citadina desde as primeiras tramas urbanas às mais complexas 
formas de organização socioespacial, em que a aventura do urbano transcorre no palco das formas espaciais protagonizado pelas práticas sociais ali presentes, o que Lepetit (2001, p. 20) tratava como "a relação indissociável entre os grupos sociais e a configuração material das cidades". Uma relação simbiótica que impõe sempre pensar de forma integrada cidade e prática social, porque a vida urbana ocorre, invariavelmente, na articulação dessas duas esferas - espaço e sociedade - e se conjuga no presente e é feita de cruzamentos.

Percorrer a trajetória da cidade no tempo e nela identificar ambientes que se fizeram propícios ao desenvolvimento do debate e consolidação das opiniões coletivas é uma maneira de conjugar essas duas esferas e nelas reconhecer um cruzamento socioespacial. Da polis à cidade moderna, da assembleia ao ciberespaço, a história nos informa que os ambientes de convivência pública nas cidades se colocam como os espaços favoráveis ao convívio produtor de sociabilidades e opiniões. São as práticas sociais exercidas nesses espaços que fomentam, consolidam e enriquecem a opinião pública.

Balizados pela obra de Habermas (2003), identificamos ambientes que na história serviram de palco para afirmação das ideias coletivas, reconhecendo lugares urbanos que historicamente acolheram a produção social da opinião pública e os novos ambientes e utensílios midiáticos. A Ágora - pela sua versatilidade social de fazer conviver simultaneamente praça, mercado e política - foi o ambiente que inaugurou e melhor incorporou a ideia de espaço da construção de opiniões; mesmo sob intensa força e poder, a dominação do Império Romano não conseguiu fazer calar completamente a opinião pública que ao ganhar as ruas forçava sua separação dos canais oficiais; sem vínculo de obrigatoriedade na contraposição das esferas pública e privada, a ordem social medieval conviveu com a ausência de um espaço agregador do diálogo e disseminador de ideias, uma vez que o espaço público era regido pelo poder privado; norteada pelo mercado, surge, então, a modernidade burguesa e uma esfera pública de conteúdo não estatal e sua expansão está diretamente vinculada ao crescimento das cidades e das utensilagens que 0 universo urbano pôde ofertar às novas formas de sociabilidades, às práticas sociais e à produção da opinião.

Por mais que as novas utensilagens de produção e difusão da opinião pública - falamos aqui especificamente acerca dos atuais instrumentos midiáticos - possam apresentar um registro da pluralidade social, elas têm a propriedade de conceber a cidade e o universo urbano como um ambiente muito mais homogêneo do que realmente são. Na tentativa de realizar uma "linguagem universal" acabam pasteurizando aquilo que justamente deveria aflorar como plural, conduzindo o novo espaço público à monofonia ao invés de imprimir-lhe um caráter de lugar de inovações e mudanças.

Talvez seja pouco provável, como também soe exagerado considerar que as novas tecnologias da informação, a Internet especificamente, farão do ciberespaço a nova esfera pública em que ocorrerão todos os intercâmbios, transações comerciais e processos comunicacionais. Uma ideia eivada da presunção da onipresença. De mesmo modo, podemos incorrer em grave erro imaginarmos que as infovias digitais ou as autoestradas da informação nos conduzirão por caminhos igualitários e democráticos, ou a ambientes embebidos pela 
cultura do espaço público, desaguando em um enorme carnaval das múltiplas identidades.

Certo é que aos poucos vamos perdendo a capacidade de apreender a cidade por experiências diretas, como fazia o Flâneur da Paris de Baudelaire ou o cronista João do Rio, do Rio de Janeiro da Primeira República. Os instrumentos midiáticos, ao tentar garantir a comunicação, o debate e a convivência urbana, não produzem o resultado das formas diretas de interação como outrora realizavam as praças. Essas "novas praças" mediadas criam novos atores sociais, geram novos significados à esfera pública e estabelecem novos espaços sociais de produção da opinião. No entanto, não são as novas utensilagens que definirão a natureza dos lugares de produção da opinião, mas, certamente, serão as práticas sociais e aquilo que construirmos como ordenamento social que continuarão a impulsionar tais ambientes, em uma cidade que não se cansa de refazer-se historicamente.

\section{Maria da Penha Smarzaro Siqueira}

Universidade Federal do Espírito Santo, Universidade Vila Velha, Programa de Pós-Graduação em Sociologia Política. Vila Velha/ES, Brasil.

penhasiq@hotmail.com

\section{Gilton Luis Ferreira}

Prefeitura Municipal de Aracruz, Secretaria de Planejamento, Orçamento e Gestão. Aracruz/ES, Brasil. gilton87@hotmail.com

\section{Notas}

(1) Falamos aqui, mais especificamente, da Segunda Revolução Industrial ou Revolução Científico-Tecnológica, muito mais complexa, ampla e profunda do que um mero desdobramento da primeira. Dando um salto qualitativo como quantitativo em relação à primeira manifestação da economia mecanizada. Resultando da aplicação das mais recentes descobertas científicas aos processos produtivos, esste processo revolucionário possibilitou o desenvolvimento de novos potenciais energéticos, como a eletricidade e os derivados de petróleo, dando assim origem a novos campos de exploração industrial, como: os altos-fornos, as indústrias químicas, novos ramos metalúrgicos, como os do alumínio do níquel, do cobre e dos aços especiais, além de desenvolvimentos na área de microbiologia, bacteriologia e bioquímica, com efeitos dramáticos sobre a população e conservação de alimentos, ou na farmacologia, medicina, higiene e profilaxia, com um impacto decisivo sobre o controle das moléstias, a natalidade e o prolongamento da vida (Sevcenko, 1998, pp. 8-9). 
(2) Uma série de revoluções na Europa Central e Ocidental eclodiram em função de regimes governamentais autocráticos, de crises econômicas, de falta de representação política das classes médias e do nacionalismo, ficaram conhecidas como revoluções de 1848 . Abalaram as monarquias da Europa onde tinham fracassado as tentativas de reformas políticas e econômicas. Também chamada de Primavera dos Povos, esste conjunto de revoluções, de caráter liberal, democrático e nacionalista, foi iniciado por membros da burguesia e da nobreza que exigiam governos constitucionais, e por trabalhadores e camponeses que se rebelaram contra os excessos e a difusão das práticas capitalistas (Ferreira, 2009, p. 55).

\section{Referências}

BENEVOLO, L. (2001). História da cidade. São Paulo, Perspectiva.

CANCLINI, N.G.(2002).Cidadesecidadãosimaginadospelosmeiosdecomunicação. Disponível em:http:// www.scielo.br/scielo.php?script=sci_arttext\&pid=S0104-62762002000100003\&lng=pt\&nrm =iso. Acesso em: 9 ago 2012.

CASTELLS, M. (1999). A sociedade em rede. São Paulo, Paz e Terra.

EIRÓ-GOMES, M. e DUARTE, J. (2005). Públicos “virtuais" para cidades "reais". Disponível em: http:// www.bocc.ubi.pt/pag/eiro-gomes-duarte-publicos-virtuais-cidades-reais.pdf. Acesso em: 15 ago 2012.

FERRARA, L. D’A. (1990). As máscaras da cidade. Revista da USP. São Paulo, v. 1, n. 5, pp. 3-10.

FERREIRA, L. G. (2009). Um desejo chamado metrópole: a modernização da cidade de Vitória no limiar do século XIX. Dissertação de Mestrado. Vitória, Universidade Federal do Espírito Santo.

FRASER, N. (1996). "Rethinking the public sphere: a contribution to the critique of actually existing democracy". In: CALHOUN, C. (ed). Habermas and the public sphere. Cambridge, MIT Press.

FREITAS, J. S. de; MAMEDE, J. e LIMA, M. C. (2002). Espaço de fluxos em projetos de ciber-cidades. Disponível em http://www.bocc.ubi.pt/pag/ mamede-jose-freitas-lima-cibercidades.pdf. Acesso em: 15 ago 2012.

GRAHAM, S. (1995). "Cyberspace and the city". In: Town and Country Planning. Disponivel: http:// www.ncl.ac.uk/cut/docs/cspace.doc. Acesso em: 15 ago 2012.

GUEDES, E. N. (2010). Espaço público contemporâneo: pluralidade de vozes e interesses. Disponível em: www.bocc.ubi.pt. Acesso em: 15 ago 2012.

HABERMAS, J. (2003). Mudança estrutural da esfera pública: investigações quanto a uma categoria da sociedade burguesa. Rio de Janeiro, Tempo Brasileiro.

LE GOFF, J. (1999). Por amor às cidades. Lisboa, Teorema.

LOSEKANN, C. (2009). A esfera pública habermasiana, seus principais críticos e as possibilidades do uso deste conceito no contexto brasileiro. Pelotas, Pensamento Plural.

LUBENOW, J. A. (2007). A categoria de esfera pública em Jürgen Habermas. Tese de doutorado. Campinas, Universidade Estadual de Campinas. 
MACEDO, B. de (1986). A opinião pública na História e a História na opinião pública. Disponível em: http://www.ieei.pt/documentacao/documentos/BM_A_opiniao_publica_na_Historia.pdf. Acesso em: 9 jul 2012.

MELO, P. B. de (2005). Um passeio pela História da Imprensa: o espaço público dos grunhidos ao ciberespaço. Revista Comunicação \& informação, Faculdade de Comunicação e Biblioteconomia da Universidade Federal de Goiás, v. 8, n. 1, pp. 26-38.

MUMFORD, L. (2004). A cidade na história: suas origens, transformações e perspectiva. São Paulo, Martins Fontes.

NARCISO, C. A. F. (2008). Espaço público: desenho, organização e poder: o caso de Barcelona. Dissertação de Mestrado. Lisboa, Universidade de Lisboa. Disponível em: http://repositorio. ul.pt/handle/10451/1736.

NASCIMENTO, S. (2002). Mediaticamente Homem Público: sobre a dimensão electrónica dos espaços públicos. Disponível em: http://www.bocc.ubi.pt/_esp/autor.php? codautor=614 Acesso em: 15 ago 2012.

OTA, M. E. (2013). A dicotomia público/privado revisitada: uma crítica feminista às teorias morais. Disponível em: http://revistaseletronicas.pucrs.br/ojs/index.php/intuitio/\%20 issue/view/750. Acesso em: 9 fev 2014.

PERLATTO, F. (2012). Habermas, a esfera pública e o Brasil. Revista de Estudos Políticos do Núcleo de Estudos em Teoria Política. NUTEP/UFRJ, v. 1, n. 4, pp. 78-94.

PESAVENTO, S. J. (1997). Exposições Universais: espetáculos da modernidade do século XIX. São Paulo, Hucitec.

(2002). O Imaginário da Cidade: visões literárias do urbano - Paris, Rio de Janeiro, Porto Alegre. Porto Alegre, Editora da UFRGS.

RESENDE, F. (2005). A comunicação social e o espaço público contemporâneo. Disponível em: http://revistaalceu.com.puc-rio.br/cgi/cgilua.exe/sys/start.htm?from_info_index=9 \&infoid=182\&sid=22. Acesso em: 9 fev 2014.

SEVCENKO, N. (1998). História da vida privada no Brasil. São Paulo, Companhia das Letras.

SILVA, A. (1996). Nuevas fantasías en las noticias de televisión. Disponível em: http://www.redalyc. org/pdf/115/11500907.pdf. Acesso em: 9 fev 2014.

THOMPSON, J. (1998). A mídia e a modernidade: uma teoria social da mídia. Petrópolis, Vozes.

VERNIK, E. (1996). Comunidades cercadas: la exclusión urbana en la televisión y en la vida. Disponível em: http://www.redalyc.org/pdf/115/11500906.pdf. Acesso em: 9 fev 2014.

Texto recebido em 11/ago/2014

Texto aprovado em 29/out/2014 